\title{
Poder estrutural e sua utilização pelas corporações como ferramenta de dominação do mundo globalizado
}

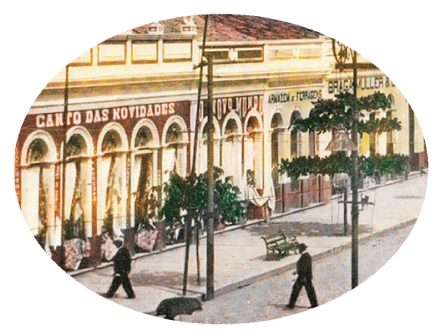

Frederico Nicolau Cesarino*

\section{Resumo}

Desde o início da revolução industrial, há mais de dois séculos, a tecnologia moderna tem radicalmente aumentado ou aprimorado a produção, os transportes e comunicações em todo o mundo. Durante o período, a população humana mundial cresceu de um bilhão para mais de sete bilhões, e surgiu-se uma rede de interligação mundial entre os indivíduos. $\mathrm{Na}$ busca por recursos naturais (alimentos, combustíveis e outras matérias-primas) e por mercados para os produtos industrializados, as corporações trabalham, negociam, colaboram e competem entre si, transformam a cultura e o meio ambiente através de seu poder estrutural. Assim, essa dinâmica de ações causa, ao mesmo tempo, benefício para um determinado grupo e uma gama de prejuízos de diversos tipos para uma grande massa populacional.

Palavras-chave: Globalização; poder estrutural; poder brando; empresas Multinacionais.

\footnotetext{
* Engenheiro mecânico e matemático. Aluno do curso de mestrado em sociologia pela Universidade Federal do Amazonas (UFAM).E-mail: fcesarino@hotmail.com
} 


\begin{abstract}
Since industrial revolution first days, over two centuries ago, modern technology radically changed industrial production, transportation and communications all over the world. During this time, world population increased from one billion to seven billion people, and a person-to person world network appeared. In order do find natural resources and new markets for their products, corporations work hard, battle with other corporations for the market share, and change the culture and physical environment after using their structural power. This action dynamics is responsible for giving huge profits and benefits to a small social group and big losses, of many kinds, to an immense population mass.
\end{abstract}

Keywords: Globalization; hard power; soft power; worldwide companies.

\title{
Apresentação
}

Uma característica do capitalismo é a busca incessante por novos mercados consumidores. Ilustre-se, por exemplo, a ação dos Estados Unidos e as nações europeias desenvolvidas: quando se esgotam os recursos naturais, limitam-se as possibilidades da transformação de matérias-primas em produto acabado, ou quando a oferta de produtos industrializados cresce a ponto de não encontrar compradores, estas nações (representadas por suas empresas estatais ou privadas) passam a almejar a ampliação do comércio através da conquista de novos espaços no globo.

Assim ocorreu desde as origens do capitalismo no século XVI, com a expansão ultramarina de Portugal e Espanha. No século XIX, a formação do Império Britânico deu continuidade a esse processo, e em seguida a conquista e colonização da África pela França, Itália, Inglaterra e Alemanha. Mais recentemente, após o final da Segunda Guerra Mundial, o mundo assistiu o crescimento econômico dos Estados Unidos, o qual se tornou a primeira potência mundial, que realiza empréstimos e financiamentos a outras nações e exporta seus produtos e empresas pelo mundo.

Os exemplos acima permitem afirmar que esta formação econômica e social possui uma vocação para conquistar o planeta: as lutas por novos mercados, a ampliação do comércio exterior e a expansão das ideias e da moral 
burguesas. Assim, a denominada globalização não é um fenômeno recente. Mas então por que se fala tanto em globalização nos dias atuais?

A resposta está diretamente ligada ao fato que, a partir da última década do século XX, ocorre uma acentuação dos fenômenos ocorridos nos séculos anteriores. As novas tecnologias de comunicação e da eletrônica encurtaram as distâncias geográficas entre os mercados. Tem-se, deste modo, que:

O capital é gerenciado vinte e quatro horas por dia em mercados financeiros globalmente integrados, funcionando em tempo real pela primeira vez na história: transações comerciais no valor de bilhões de dólares são realizadas em questão de segundos, através de circuitos eletrônicos espalhados por todo o planeta (CASTELLS, 1999, p. 111).

É importante também salientar que a globalização não se restringe apenas à reorganização mundial da economia. Junto com essa característica, a globalização tem implicações no campo da política e da cultura. Boaventura de Souza Santos (1997) dá uma importante definição desse conceito polêmico. Para o autor, a globalização pode ser compreendida através de quatro situações definidas, a seguir:

1. O localismo globalizado, que se constitui na possibilidade histórica de países centrais e poderosos imporem tantos fenômenos locais como globais aos países periféricos e com menos poder. Um grande exemplo é a disseminação da língua inglesa como língua global.

2. O globalismo localizado, como sendo o impacto social que uma determinada região sofre em conseqüência do localismo globalizado como, por exemplo, a influência da língua inglesa no cotidiano do brasileiro.

3. O cosmopolitismo, que consiste nas ações das classes trabalhadoras e de setores organizados na perspectiva destas classes, as quais procuram se utilizar dos mecanismos de contato e informação criados pelo sistema mundial. Como exemplo, tem-se as redes de comunicação via internet, os movimentos sindicais e feministas internacionais, e os fóruns mundiais de defesa de direitos humanos. 
4. O patrimônio comum da bumanidade, que consiste no conjunto de temas que apenas ganham sentido quando tratados como temas globais. Por exemplo, os meios que garantem a defesa da vida, a defesa do meio ambiente, entre outros.

Para Boaventura de Sousa Santos, o localismo globalizado e o globalismo localizado são globalizações que favorecem as elites mundiais, as quais representam a grande burguesia proprietária do capital. Já o cosmopolitismo e o patrimônio comum da bumanidade são o resultado das lutas democráticas e movidas pelas classes trabalhadoras, ou dos setores comprometidos com essas classes. Assim, a globalização é um conceito polêmico, pois tanto pode indicar movimentos de defesa dos interesses populares como designa as forças do capital contra a vida. Trata-se, portanto, da população mundial lutar e fazer uso das novas tecnologias a serviço da vida, e não o contrário.

Karl Marx: a tendência da formação de uma sociedade econômica globalizada

Possivelmente, o primeiro autor a relatar quais os rumos econômicos e sociais que o mundo se encaminhava foi Karl Marx. Ao escrever o clássico Manifesto do partido comunista, Marx não pretendia fazer previsões a respeito da economia mundial futura. No entanto, visualizava a tendência da criação de um mundo globalizado, sem fronteiras para a circulação de bens, capital e mão de obra:

A antiga organização feudal da indústria, em que esta era circunscrita a corporações fechadas, já não podia satisfazer às necessidades que cresciam com a abertura de novos mercados. A manufatura a substituiu. A pequena burguesia industrial suplantou os mestres das corporações; a divisão do trabalho entre as diferentes corporações desapareceu diante da divisão do trabalho dentro da própria oficina. Todavia, os mercados ampliavam-se cada vez mais: a procura de mercadorias aumentava sempre. A própria manufatura tornou-se insuficiente; então, o vapor e a maquinaria revolucionaram a produção industrial. A grande indústria moderna suplantou a manufatura; a média burguesia manufatureira cedeu lugar aos milionários da indústria, aos chefes de verdadeiros exércitos industriais, aos burgueses 
modernos. A grande indústria criou o mercado mundial preparado pela descoberta da América: o mercado mundial acelerou prodigiosamente o desenvolvimento do comércio, da navegação e dos meios de comunicação por terra. Este desenvolvimento reagiu por sua vez sobre a extensão da indústria; e, à medida que a indústria, o comércio, a navegação, as vias férreas se desenvolviam, crescia a burguesia, multiplicando seus capitais e relegando a segundo plano as classes legadas pela Idade Média (MARX, 2010, p. 7).

Uma sociedade globalizada seria nociva ao cidadão comum, e a prevenção deste mal se daria, segundo o autor, através de uma revolução do proletariado em desfavor da burguesia e a subsequente implantação de um regime socialista.

Tais regimes sonhados por Marx foram de fato instaurados em várias partes do mundo (em especial na Europa Oriental) a partir do início do século $\mathrm{XX}$. Tais regimes nem sempre foram gerados por meio de revoluções das classes trabalhadoras assalariadas, e sim por decisões políticas ou imposição de outra nação com influência regional. Certamente a imposição deste regime a algumas nações, sem apoio popular, tornou difícil a manutenção deste sistema em grande escala regional. Desse modo, a partir do início da década de 1990 e com a dinamização dos meios de comunicação, ocorreu a ruptura política e econômica do sistema socialista, e assim abriram-se as portas para uma "contrarrevolução" do capitalismo. Essa ação acabou por confirmar o que Marx sinalizava (e condenava) em seus escritos, e possivelmente nunca o capitalismo tenha tido tanto poder de influência na sociedade como nos últimos vinte anos da história mundial contemporânea.

Empresas de capital global perceberam, na ruptura do antigo bloco socialista, um terreno virgem e extremamente fértil para a expansão de suas atividades capitalistas. Empresas locais em processo de desestatização permitiam aos grandes conglomerados globais a fixação na localidade (por meio da aquisição ou associação com estas empresas locais), e uma considerável quantidade de cidadãos foi "convertida" em mercado consumidor por meio de maciça propaganda. Os novos consumidores passaram a ter "necessidades" de bens de consumo dos quais nunca haviam tido conhecimento de sua existência durante o regime socialista.

Há duas cenas muito lembradas em relação a essas novas necessidades: 
a inauguração da primeira unidade de uma empresa americana de fast food em Moscou, em 1992, tornou-se manchete nos noticiários mundiais ao mostrar uma fila de espera de cinco horas para se comprar um sanduíche. Outra imagem é a de um fato ocorrido tão logo ocorreu a queda do muro de Berlim, quando alemães orientais simplesmente abandonavam seu automóveis Lada ou Trabant nas ruas e imediatamente compravam modelos de marcas "ocidentais" para ostentá-los na nova Alemanha capitalista. Ou seja, antes da ruptura oficial do regime socialista nesses países, o capitalismo de alguma forma já havia conseguido mostrar seu poder à população e ao governo daquelas nações.

Pela exploração do mercado mundial a burguesia imprime um caráter cosmopolita à produção e ao consumo em todos os países. Para desespero dos reacionários, ela retirou à indústria sua base nacional. As velhas indústrias nacionais foram destruídas e continuam a sê-lo diariamente. São suplantadas por novas indústrias, cuja introdução se torna uma questão vital para todas as nações civilizadas, indústrias que não empregam mais matérias-primas autóctones, mas sim matérias-primas vindas das regiões mais distantes, e cujos produtos se consomem não somente no próprio país mas em todas as partes do globo. Em lugar das antigas necessidades, satisfeitas pelos produtos nacionais, nascem novas necessidades, que reclamam para sua satisfação os produtos das regiões mais longínquas e dos climas mais diversos (MARX, 2010, p. 8).

Tais grupos empresariais que atuam em escala mundial representam, na economia contemporânea, a burguesia dominante tão criticada por Marx. Vale observar que o autor destaca o fato de, em toda a História, a burguesia ter desempenhado papel fundamental em todos os processos revolucionários, infiltrando-se nas relações macro e microeconômicas, políticas e até mesmo nos costumes familiares, como pode ser verificado a seguir:

A burguesia desempenhou na História um papel eminentemente revolucionário. Onde quer que tenha conquistado o poder, a burguesia calcou aos pés as relações feudais, patriarcais e idílicas. Todos os complexos e variados laços que prendiam o homem feudal a seus "superiores 
naturais" ela os despedaçou sem piedade, para só deixar subsistir, de homem para homem, o laço do frio interesse, as duras exigências do "pagamento à vista". Afogou os fervores sagrados do êxtase religioso, do entusiasmo cavalheiresco, do sentimentalismo pequeno-burguês nas águas geladas do cálculo egoísta. Fez da dignidade pessoal um simples valor de troca; substituiu as numerosas liberdades, conquistadas com tanto esforço, pela única e implacável liberdade de comércio. Em uma palavra, em lugar da exploração velada por ilusões religiosas e políticas, a burguesia colocou uma exploração aberta, cínica, direta e brutal (MARX, 2010, p. 8).

É importante destacar que o objetivo principal da burguesia, segundo o autor, é a obtenção de lucros milionários. O sistema capitalista, em contraposição ao socialismo, não prevê a proteção dos fracos, benefício dos pobres, apoio aos doentes, favorecimento de pequenos produtores ou preservação do meio ambiente. A política da burguesia é, desde então, promovida por meio de conceitos específicos como o "livre comércio", "mercado livre" e "liberdade de empreendimento". O sucesso comercial desses empreendimentos, nacionais ou multinacionais, sempre acarreta um ônus, geralmente pago por povos nativos, pequenos agricultores, pastores, artesãos, pescadores, entre outros grupos. De acordo com o ponto de vista dessas pessoas, tais conceitos de liberdade burguesa representam outro conceito, denominado "capitalismo selvagem", o qual descreve a ordem mundial na qual os mais fracos estão frequentemente condenados à pobreza e à miséria.

\section{Poder estrutural: a força da globalização}

O capitalismo internacional tem se expandido através de um novo modelo, desde o início da década de 1990. Operado sob o conceito de globalização, é baseado nas estruturas das antigas redes mundiais de comércio e sucede um sistema colonial no qual algumas nações capitalistas poderosas, especialmente europeias, governavam e exploravam nações estrangeiras em territórios distantes.

O processo de globalização é dinamicamente estruturado, apesar de ser extremamente complexo e turbulento. Assim, os indivíduos, empresas e 
instituições políticas reorganizam e reestruturam a área política para obterem vantagens competitivas, através da disputa pelos recursos naturais, mão de obra barata, novos mercados comerciais e lucros maiores. Ao ser considerado todo o globo como espaço competitivo, faz-se necessária a obtenção do maior poder possível para o sucesso de cada operação. Por poder, entende-se como "a habilidade dos indivíduos para impor seus desejos sobre outros e obrigá-los a executar determinadas ações, mesmo contra sua própria vontade" (MCBRIDE, 2011, p. 441). O poder pode ser aplicado para imposição e manutenção da lei e da ordem, as quais coordenam, regulam e controlam o comportamento coletivo em uma comunidade ou sociedade específica, e também fora dela.

Existem diferentes níveis de poder nas sociedades, assim como entre as mesmas. Eric Wolf (1999) destacou a importância de ser estendido o nível macro de poder, chamado de poder estrutural, o qual organiza e administra a interação sistêmica na sociedade e entre elas, com a direção das forças econômicas e políticas, além das forças ideológicas as quais moldam ideias, crenças e valores. O conceito de poder estrutural não se aplica apenas às organizações políticas, mas também faz parte das novas forças globais complexas as quais reestruturam e remodelam as sociedades e ambientes em todo o planeta.

$\mathrm{Na}$ busca por tentar influenciar os Estados, as corporações multinacionais exercem o poder estrutural. O mesmo está associado com a importância relativa da empresa nas economias nacionais. Em outras palavras, as economias nacionais, em maior ou menor grau, são estruturalmente dependentes do capital (BERHANGEN, 2003; GILL; LAW, 1993). Dessa forma, o poder estrutural das empresas multinacionais invariavelmente está ligado com o porte da empresa e com a questão da mobilidade do capital. Quanto maior for a empresa, em termos globais, maior deverá ser o seu poder estrutural. Entretanto, o poder estrutural não é uma medida absoluta, e sim, relativa, ou seja, uma empresa deve ser mais ou menos poderosa em relação a um Estado, dependendo do grau de dependência estrutural deste Estado em relação ao capital. Em outras palavras, o poder estrutural das empresas multinacionais em relação aos Estados poderia ser medido resgatando-se os conceitos de sensibilidade e vulnerabilidade apresentados por Keohane e Nye (2001). A sensibilidade diz respeito ao grau de resposta a uma política: o quão rápido um país traz mudanças custosas aos outros países e o quão grande são esses custos. Já a vulnerabilidade diz respeito à disponibilidade e ao custo das alternativas 
diante da situação de interdependência.

\section{Poder estrutural militar e sua influência nos mercados globais}

Atualmente os Estados Unidos possuem poder militar superior a qualquer um de seus aliados ou rivais em todo o mundo. É o líder mundial em despesas militares, seguido pela Comunidade Europeia e China. De fato, como superpotência dominante, os Estados Unidos são responsáveis por quase metade de cerca de 1,5 trilhão gastos em armas em todo o mundo. Além disso, apesar de existirem outras nações com poderio bélico composto também por armas nucleares, o maior arsenal pertence, sem dúvidas, aos Estados Unidos e à Rússia, com aproximadamente 5.800 ogivas operacionais para cada nação (NORRIS, 2006).

Em paralelo ao poder militar, há a utilização da força econômica como instrumento político de coerção ou intimidação no processo de estruturação global. Entre outras coisas, isso significa que o tamanho e a produtividade econômica, capacidade tecnológica e capital financeiro podem ser empregados para apoiar o mercado global, o que forçam Estados mais fracos a quebrar as barreiras comerciais as quais protegem seus trabalhadores, seus recursos naturais e mercados locais.

Os Estados Unidos, como maior economia do mundo e líder em exportações, há muito pressionam o livre comércio para suas corporações as quais realizam negócios em escala global. Em toda sua história, às vezes utilizase do poder militar para impor mudanças em uma região política estrangeira através de intervenções armadas ou invasões em grande escala. Esse fato para muitos é visto como ameaça sempre presente, pronta para aplicação de uma força militar esmagadora a fim de beneficiar os interesses corporativos, seja qualquer seu segmento de atuação comercial. As corporações, por sua vez, exercem enorme influência financeira e política sobre os governos e as organizações governamentais, até mesmo sobre a Organização Mundial do Comércio e as instituições financeiras globais, como o Banco Mundial e o Fundo Monetário Internacional, estes com sede na própria capital dos Estados Unidos.

Como possui mais corporações mundiais do que qualquer outra nação, os Estados Unidos se empenham para a proteção militar e econômica de seus 
interesses, com investimentos chamados, pelos estadunidenses, de ambiente de segurança mundial. ${ }^{1}$ Muitos outros países, incapazes ou impedidos de produzir ou sustentar sistemas bélicos caros, tem investido em tecnologias de armas químicas e biológicas, ou empregam como tática bélica a guerrilha e o terrorismo em suas estratégias locais, regionais ou mesmo globais.

\section{O surgimento das corporações globais e o poder estrutural econômico}

As corporações globais, a partir da segunda metade do século XX, se tornaram uma força política e econômica muito abrangente em todo o mundo. Alguns gigantes empresariais, como a General Electric, Siemens, Shell e Toyota são, na verdade, grupos de várias corporações unidas por laços de propriedade comum e que seguem uma estratégia administrativa comum. Em geral são controladas por um escritório central estabelecido em um país, e organizam sua produção em diferentes países para atender os interesses formulados pelo alto escalão hierárquico corporativo, muitas vezes sem a devida preocupação se estes interesses estão de acordo com os interesses da população dos países nos quais operam. Essas grandes corporações são o produto de uma revolução tecnológica, a qual permitiu a existência de uma logística de transportes mais eficiente, aliada à transmissão de dados e informações globais em tempo real, que permitiram a supervisão e gerenciamento das operações globais de modo eficiente e adequado.

O poder das grandes empresas que operam globalmente é tão grande que as mesmas, cada vez mais, contrariam os desejos dos governos nacionais ou de organizações como a Cruz Vermelha, Organização das Nações Unidas e o Tribunal Internacional de Justiça. Uma vez que as informações processadas pelas corporações não fluem de modo significativo para a população em geral (ou mesmo para os níveis inferiores da própria organização), os governos têm dificuldades na obtenção dos dados necessários para a tomada de decisões políticas. Além disso, as corporações globais têm repetidamente demonstrado que são capazes de invalidar as decisões políticas estrangeiras. Embora, para alguns, este fato seja considerado um sinal de que as disputas e rivalidades nacionais estão sendo extintas, a verdade é que o mercado global tem sido, cada vez mais, controlado pelas corporações provadas extremamente grandes e poderosas, interessadas somente no lucro financeiro. Tem-se, como exemplo: 
Atualmente, as cem maiores companhias controlam 33\% dos bens mundiais, mas empregam apenas $1 \%$ da força de trabalho de todo o mundo. A General Motors é maior que a Dinamarca. Walmart é maior que a África do sul. As megacorporações percorrem o mundo livremente, influenciando legisladores para obter medidas favoráveis, financiando eleições e colocando governos um contra o outro, a fim de obter melhores negócios. Elas controlam grande parte das notícias mundiais e o fluxo de informações (HERTZ, 2001, p. 43)

As corporações globais estão modificando o mundo e a vida das pessoas de todas as profissões e classes sociais, até mesmo a dos próprios empregados. Na busca por mão de obra barata as empresas, por exemplo, utilizam a prática da contratação de mulheres para os serviços os quais exigem pouca qualificação profissional. Ainda, a relação impessoal entre produtores e consumidores, entre os quais há uma distribuição desigual de poder, exige como consequência um grande senso de indiferença, apatia, e mesmo a perda de confiança no próprio sistema considerado desumano. Quando um trabalhador não possui a devida confiança em seu chefe, e determinado chefe não confia em seu gerente, as relações de produção ficam prejudicadas ou arruinadas em todos os níveis. Como tais sistemas são gerados e mantidos por seres humanos, este estranhamento pode, por fim, provocar um colapso do sistema. Uma vez que a produção, comércio e operações financeiras fazem parte de um sistema globalizado, o colapso em parte dele pode desencadear uma reação em cadeia mundial de fracassos, como ocorreu, por exemplo, na crise global provocada pela falência de várias empresas sediadas nos Estados Unidos e mal administradas, em 2008.

\section{O poder brando}

As corporações globais, para defender os seus interesses contam, ainda, com o denominado poder estrutural brando (ou soft power ${ }^{2}$. Conforme definido por Nye (2004, p. 5), o poder brando é refletido na capacidade de se conseguir os resultados de sua preferência cooptando as pessoas ao invés de coagi-las. 
Portanto, trata-se da capacidade de um ator dar forma às preferências de outro ator, através de seu poder de atração e sedução. O poder brando é mais que persuasão, pois as pessoas são levadas a concordar por se sentirem atraídas por aquilo que determinado ator representa. A atração nem sempre determina as preferências de um determinado ator, mas, certamente, pode alterar a sua percepção e, indiretamente, influenciar o resultado desejado pelo ator com o poder brando (SARFATI, 2009). Embora Nye (2004, p. 90-97) reconheça que atores não estatais possuem este poder, ele não detalha a natureza do mesmo em relação às empresas globais. O poder brando destas nas relações internacionais está associado às identidades do consumidor/cliente, no nível micro, e dos Estados, no nível macro, com as atividades da empresa desenvolvidas no país.

O poder brando de uma empresa pode vir de sua imagem, por meio do “marketing” que constrói uma identificação com o público em geral, e de sua relação com as comunidades epistêmicas, especialmente as científicas, onde os grupos epistêmicos são fonte de legitimação da atividade corporativa. O poder brando mais antigo e reconhecível das corporações é a identificação do consumidor com a marca da empresa. Um dos elementos fundamentais da estratégia de marketing de qualquer empresa é criar o chamado brand awareness, ou seja, o reconhecimento público em relação a uma marca. Fundamentalmente, as empresas buscam tornar as suas marcas reconhecidas, pois isso cria uma diferenciação em relação às outras empresas possibilitando não só a sobreposição à concorrência, mas também a garantia de credibilidade junto ao consumidor, para que as linhas futuras de produtos sejam continuamente adquiridas, uma vez que o consumidor respeita e gosta do estilo de determinada marca. Outra estratégia institucional usada em escala global, associada ao poder brando das empresas, é direcionar recursos para a filantropia. Segundo Rondinelli (2002, p. 394), as empresas, juntamente com ricos executivos, têm cada vez mais assumido o papel público de fornecimento de ajuda internacional através do desenvolvimento de programas filantrópicos. Ainda, segundo o mesmo autor, as empresas são hoje responsáveis por aproximadamente $87 \%$ da ajuda aos países pobres, com cerca de US\$296 bilhões. São numerosos os exemplos de filantropia apoiados pelas corporações, dos quais se pode citar: a parceria Coca-Cola e Rotary Internacional, para ajudar o governo da Índia a imunizar a população contra a poliomielite; e o fundo da Nokia, de US\$ 11 milhões, montado com a ajuda de seus empregados voluntários, para ajudar a ensinar crianças com dificuldade de aprendizado na África do Sul, China, México, 
Brasil, Inglaterra e Alemanha (RONDINELLI, 2002, p. 395).

Ou seja, o poder brando é o poder que pressiona por intermédio da atração e persuasão a mudança de ideias, crenças, valores e comportamentos. Embora a propaganda seja uma forma (e certamente a mais difundida) de poder brando, o exercício da influência ideológica (a luta global pelos corações e mentes) também opera através de meios mais sutis, como a ajuda estrangeira, diplomacia internacional, noticiários, esportes, entretenimento, exposições e intercâmbios acadêmicos.

\section{O ambiente de mídia global e o poder brando}

Em sua busca global pela dominação de mercado e pelos lucros, os estados e corporações que competem entre si utilizam-se da persuasão ideológica do poder brando transmitida por meio da mídia eletrônica e digital, dos satélites de comunicação e demais tecnologias de informação. Uma de suas principais tarefas é proceder com a organização e venda das ideias gerais de globalização como algo positivo e progressivo, principalmente através dos conceitos de liberdade, livre comércio, mercado livre, mercado global; além da adaptação ou estigma de qualquer aspecto o qual se oponha em termos negativos ao capitalismo.

As corporações globais de mídia em massa (CNN, BBC e NBC, por exemplo) possuem muito poder brando. A CNN, por exemplo, é uma empresa privada que produz e distribui notícias e outras informações por meio de redes internacionais de transmissão a cabo e satélites, assim como pela internet. Possui escritórios em aproximadamente trinta países, possui cobertura contínua e seu público é estimado em aproximadamente dois bilhões de pessoas em todo o mundo. E, juntamente com os demais conglomerados de mídia, seleciona as imagens as quais serão exibidas e ainda determina o que deve ser enfatizado ou reprimido. Através da utilização do poder brando, influenciam a percepção e a ação do público.

Nos últimos anos, o poder das corporações tem se tornado cada vez mais abrangente através da expansão da mídia. Nas últimas duas décadas, houve o desenvolvimento de um sistema de mídia comercial global dominado por algumas poucas megacorporações, a maioria com sede nos Estados Unidos. O controle da televisão e de outras mídias, assim como da indústria publicitária, proporciona a estas corporações a obtenção de uma enorme influência sobre 
as ideias e o comportamento de milhões de pessoas comuns em todo o planeta, de modo que a maioria dessas pessoas não suspeita nem imagina esta influência.

\section{Reações à globalização, à modernidade e ao poder estrutural}

Mesmo que um Estado ou megacorporação possua a destreza de gerenciar o poder estrutural com eficácia, a globalização irá enfrentar oposição. Existem focos de resistência nas sociedades industriais ricas, assim como em todas as partes do mundo. Tal resistência se manifesta através do aumento de movimentos de cunho tradicionalista ou de revitalização. Ou seja, tentativas de se fazer a sociedade retornar a um estado anterior antes que venha a ocorrer, em sua concepção, uma desestruturação ou desequilíbrio na ordem familiar. Tais movimentos de reação podem se manifestar sob a forma de movimentos nacionalistas, políticos, religiosos (fundamentalistas ou não); ou movimentos de origem popular como organizações ambientalistas ou de promoção da paz.

Embora seja verdade que os Estados e as grandes corporações tenham expandido seu poder e influência por meio das tecnologias eletrônicas de comunicação, também é verdade que essas mesmas tecnologias oferecem oportunidades para grupos e indivíduos que tradicionalmente não possuem poder. Elas apresentam meios para distribuir informações e promover atividades distintas das atividades da sociedade dominante, ou que estão em oposição a elas.

Dois exemplos podem ser citados: o grupo fundamentalista Talibã, no Afeganistão, ajudou a expulsar o exército russo em seu país, e acabar com a guerra civil. Em seguida, assumiu o poder na década de 1990 e impôs uma versão radical da lei islâmica tradicional na tentativa de se criar uma república com base em valores religiosos muito rígidos. Outro exemplo se trata de uma reação semelhante, porém menos radical, a qual ocorre nos Estados Unidos. Alguns cidadãos fundamentalistas tentam moldar ou transformar não somente as próprias cidades, mas também os Estados e mesmo a nação inteira, ao eleger políticos comprometidos em criar uma cultura nacional baseada no que entendem como patriotismo norte-americano, através de valores cristãos tradicionais, utilização apenas da língua inglesa na sociedade e instituições, e segregacionismo não declarado aos negros e latino-americanos. 


\section{Considerações finais}

O poder estrutural e seus conceitos associados nos permitem melhor compreensão acerca da ampla área de força na qual as comunidades locais de todo o mundo agora são obrigadas a operar. Entender isso significa perceber como é desigual a distribuição de riqueza, saúde e poder nessa arena global.

A globalização, na verdade, faz muito mais que criar uma arena mundial na qual as megacorporações obtêm lucros gigantescos. Também devasta muitas culturas tradicionais e destrói organizações sociais há muito estabelecidas. Considerando as diferenças culturais, divisões políticas e os interesses econômicos competitivos existentes, combinados com a crescente resistência à dominação das superpotências, o sistema mundial que surge é inerentemente instável, vulnerável e imprevisível.

No início do século XXI, a tendência global da desigualdade econômica se torna clara: o pobre fica cada vez mais pobre, enquanto o rico fica cada vez mais rico. Para cada milhar de pessoas que possuem muito, há milhões que possuem pouco ou quase nada.

Não somente as megacorporações multinacionais, mas também bancos e companhias de investimento são acusados de serem insensíveis às consequências políticas, econômicas e ambientais dos projetos que favorecem. As instituições financeiras mundiais, como o FMI e o Banco Mundial, também são castigadas pelos projetos aos quais apoiam. O Banco Mundial, por exemplo, aprovou um empréstimo de 40 milhões de dólares para que o governo da China pudesse realocar alguns agricultores mais pobres, de etnia han, para uma gleba de terras férteis no território de Qingai, sendo este território considerado pelos tibetanos como de sua propriedade. Desse modo, os tibetanos protestaram contra o apoio do Banco Mundial à tentativa da China em diluir a população de minoria étnica tibetana naquela região (McBRIDE, 2011, p. 421).

Com base em sua capacidade de utilizar, dirigir e distribuir os recursos globais e o fluxo de energia, os Estados com armamento pesado, as megacorporações e as elites ricas empregam seu poder de coerção e de cooptação para estruturar ou rearranjar o sistema mundial emergente e direcionar os processos globais para seu próprio benefício competitivo. Quando esse poder estrutural arruína gradualmente o bem-estar de outros, alguns autores denominam este fato como uma violência estrutural (McBRIDE, 2011, p. 420). Desse modo, têm-se danos físicos ou psicológicos provocados 
por sistemas econômicos, políticos e sociais que atuam de forma impessoal, exploradora e injusta.

Naturalmente, as estruturas atuais estão posicionadas de modo a promover mais riqueza, poder, conforto e glória para alguns poucos felizes, enquanto gera um pouco mais que pobreza e sofrimento para muitos. Todos os dias, milhões de pessoas enfrentam fome, desastres ecológicos, problemas de saúde, instabilidade política e violência, enraizados em programas de desenvolvimento ou manobras lucrativas organizadas por Estados poderosos ou corporações globais.

A Declaração Universal dos Direitos Humanos, adotada oficialmente por todos os membros das Nações Unidas em 1948, fornece uma base útil para identificar esta violência estrutural. Os cientistas sociais tiveram papel-chave na elaboração deste documento. A introdução da declaração se inicia afirmando que "o reconhecimento da dignidade inerente a todos os membros da família humana e de seus direitos iguais e inalienáveis é o fundamento da liberdade, da justiça e da paz do mundo" (ONU, 2011). De modo geral, a violência estrutural se refere à violação sistêmica e impessoal dos direitos humanos do indivíduo e das comunidades para uma vida saudável, digna e pacífica.

Embora o abuso dos direitos humanos não seja algo novo, a globalização tem expandido e intensificado enormemente a violência estrutural por meio, por exemplo, do incremento da distância entre os mais ricos e os mais pobres, entre os mais poderosos e os sem poder algum. A violência estrutural possui incontáveis manifestações, além da pobreza. Essas manifestações variam da destruição cultural, a fome e a obesidade, a degradação ambiental, os fluxos migratórios indesejados, entre vários outros.

Face ao exposto, algumas mudanças dramáticas nos valores e nas motivações culturais, assim como nas instituições sociais e nos tipos de tecnologias empregados pelo homem, são necessárias caso o homem pretenda deixar um futuro sustentável para as próximas gerações. A ênfase exagerada no consumismo e nos interesses individuais, tão característica dos países mais ricos, precisa ser abandonada em favor de uma ética social e ambiental mais equilibrada. $\mathrm{O}$ cientista social, treinado na considerada uma das ciências mais liberais, possui uma contribuição a fazer para provocar essa mudança, pois é conhecedor dos perigos do pensamento limitado pela cultura e oferece 
uma perspectiva histórico-comparativa e cultural ao desafio de se entender e equilibrar as necessidades e desejos, muitas vezes conflitantes, de comunidades locais na era da globalização.

\section{Notas}

${ }^{1} \mathrm{O}$ termo ambiente de segurança mundial determina a sinergia entre as ações de defesa interna, poder econômico, poder diplomático e poderio bélico das nações, com o objetivo de se estabelecer um estado de "harmonia" entre as nações do globo.

$2 \mathrm{Na}$ língua inglesa, os poderes estruturais militar e econômicos também são denominados hard powers, ou "poder duro". São os poderes os quais possuem um impacto perceptível. O poder brando, por sua "sutileza" e ação subliminar, é considerado um "poder suave", ou soft power.

\section{Referências}

BERHAGEN, P. Structural Power, Information Asymmetry and Public Policy: A Signaling Model of Business Lobbying in Democratic Capitalism. Annual Meeting of the American Political Science Association. Philadelphia. 2003.

CASTELLS, M. A sociedade em rede. São Paulo: Paz e Terra, 1999.

GILL, S.; LAW, D. The Global Political Economy: Perspectives, Problems and Policies. The Johns Hopkins University Press: Baltimore, 1993.

JOHNSON, A. Dicionário de sociologia: guia prático da linguagem sociológica. Rio de Janeiro: Jorge Zahar, 1997.

KEOHANE, R.; NYE, J. S. Power and Interdependence. Harper Collins, NY, 2001

LAKATOS, E. Sociologia geral. 7. ed. São Paulo: Atlas, 2010.

MARX, K. O Capital: crítica da economia política. Tradução de Regis Barbosa e Flávio R. Kothe. 2. ed. São Paulo: Nova Cultural, 1985. (Os Economistas). . O manifesto comunista. Tradução de Maria Lucia Como. Ed. especial. Rio de Janeiro: Nova Fronteira, 2010.

McBRIDE, B. The essence of anthropology. Kansas City: Kansas State University Press, 2011. 
NYE, J. S. O Paradoxo do Poder Americano. São Paulo: Editora Unesp, 2002. . Soft Power: The Means to Success in World Politics. New York, NY: Public Affairs, 2004.

RONDINELLI, D. A. Transnational Corporations: International Citizens or New Sovereigns? Business and Society Review, v. 107, n. 4, p. 391-413, 2002.

SANTOS, B. S. Pela mão de Alice: o social e o político na pós-modernidade. 4. ed. São Paulo: Cortez, 1997.

SARFATI, G. Os limites do poder das empresas multinacionais - o caso do protocolo de Cartagena. Campinas: Editora Unicamp, 2008 Terceiro xadrez: como as empresas multinacionais negociam nas relações econômicas internacionais. São Paulo: EDUSP, 2009

WOLF, E.R. Envisioning power: ideologies of dominance and crisis. Berkeley: University of California Press, 1999. 